\title{
Psychoanalytic Contributions to the Understanding of Vulnerable Populations: A Case Illustration
}

\author{
Carol Tosone ${ }^{1}$
}

Published online: 18 November 2016

(C) Springer Science+Business Media New York 2016

Are psychoanalytic theories and practice approaches relevant to the understanding of minority populations at risk? There seems to be a perennial debate as to the merit and relevance of a psychodynamic framework, with some luminaries in the field arguing that evidence-based interventions, such as cognitive behavioral therapies, are the gold standard and psychoanalytic practice models do not pass the test of rigor (Gambrill 2010). Others (Berzoff 2012), through narrative case accounts with traditional social work populations, demonstrate the unique contributions that a psychoanalytic understanding can bring to complex, multidimensional problem situations. Some might characterize this as a science versus art approach to clinical practice, although an integrative perspective is gaining in ascendency (Barth 2014) whereby competing perspectives are considered purposely and in tandem.

In recent years, submissions to the Clinical Social Work Journal have increasingly been empirically based, innovative clinical approaches and research studies pertaining to social work topics. Far fewer submissions have been clinical case studies written by psychoanalytically-oriented social workers interested in sharing practice dilemmas, new approaches, and the like. Spearheaded by Carol Ganzer, this special issue is both a celebration of the case study and an earnest effort to showcase the multiple approaches that comprise contemporary psychodynamic and social

Carol Tosone

ct2@nyu.edu

http://www.nyu.edu/socialwork/our.faculty/carol.tosone.html http://socialwork.nyu.edu/academics/dsw-program.html http://www.springer.com/psychology/journal/10615

1 DSW Program in Clinical Social Work, Silver School of Social Work, New York University, 1 Washington Square North, Room 202, New York, NY 10003, USA work perspectives. Revisiting a case of a homeless AfricanAmerican woman she worked with decades ago, Ganzer considers how she might conceptualize the case now and invites colleagues with Lacanian, relational, case management, and numerous other perspectives to consider how best to assess and treat this woman, largely marginalized and subject to institutional racism. The result is a rashomon-like effect of how the client is viewed by each contributor, along with mosaic of useful offerings with which to understand her. These rich, competing and comparable approaches provide a multi-dimensional picture of the client and respond affirmatively to the continued value of psychoanalytic thinking in case conceptualization.

\section{References}

Barth, D. (2014). Integrative clinical social work practice: A contemporary perspective. New York: Springer.

Berzoff, J. (2012). Falling through the cracks: Psychodynamic practice with vulnerable and oppressed populations. New York: Columbia University Press.

Gambrill, E. (2010). Evidence-informed practice: antidote to propaganda in the helping professions? Research on Social Work Practice, 20, 302-320. 